\title{
EL EJERCICIO DE DERECHOS FUNDAMENTALES DE LAS PERSONAS CON DISCAPACIDAD MENTAL EN CHILE: DERECHO INTERNACIONAL, ENFOQUES TEÓRICOS Y CASOS DE ESTUDIO
}

\author{
THE EXERCISE OF RIGHTS BY PERSONS WITH MENTAL \\ DISABILITIES IN CHILE: \\ INTERNATIONAL LAW, THEORETICAL PERSPECTIVES AND \\ CASES OF STUDY
}

PABLO MARSHALL BARBERÁN***

\section{RESUMEN}

El presente trabajo aborda la necesidad de adecuar de la legislación nacional en lo que dice relación con la capacidad para ejercer derechos por parte de las personas con discapacidad mental, a la luz de las obligaciones establecidas en el art. 12 de la Convención sobre los Derechos de las Personas con Discapacidad. Se sostiene que dicha tarea se beneficiaría al identificar un marco conceptual y teórico apto para resolver problemas de ejercicio de derechos de las personas con discapacidad mental; prestar atención a los desarrollos en el derecho comparado en relación con la implementación de la Convención respecto a los regímenes de capacidad jurídica para dichas personas; y proponer estándares y determinar normas adecuadas para el ejercicio de sus derechos en las distintas áreas de sus vidas.

\footnotetext{
*Abogado, Licenciado en Ciencias Jurídicas y Sociales, Universidad de Chile. Doctor en Derecho, Universidad de Glasgow. Profesor del Instituto de Derecho Público de la Facultad de Ciencias Jurídicas y Sociales de la Universidad Austral, Valdivia, Chile. Correo electrónico: pmarshall@uach.cl. ORCID: https://orcid.org/0000-0001-8347-4620.

**Este artículo se inscribe en el proyecto de investigación FonDECYT Regular n 1190434. Se agradecen los comentarios formulados por Yanira Zúñiga y Guillermo Jiménez, coinvestigadores del Proyecto. Artículo recibido el 10 de mayo de 2019, y aceptado para su publicación el 4 de diciembre de 2019.
} 
Palabras clave: Discapacidad, personas con discapacidad mental, derechos fundamentales, derechos humanos, capacidad jurídica, convención sobre los derechos de las personas con discapacidad.

\section{ABSTRACT}

This paper addresses the need to adapt domestic legislation regarding the exercise of rights by people with disabilities, especially mental disabilities, considering the obligations set forth in Article 12 of the Convention on the Rights of Persons with Disabilities. It is argued that this task would benefit from identifying a conceptual and theoretical framework capable of solving problems of exercising rights; from paying attention to the developments of the implementation of the Convention in relation to legal capacity regimes in comparative law; and from proposing standards and determine adequate norms for the exercise of rights of people with mental disability in different areas of their lives.

Keywords: Disability, people with mental disabilities, fundamental rights, human rights, legal capacity, convention on the rights of persons with disabilities.

\section{INTRODUCCIÓN}

En marzo de 2019 se presentó una moción en la Cámara de Diputados que busca modificar "diversos textos legales con el objeto de eliminar la discriminación en contra de personas con discapacidad intelectual, cognitiva y psicosocial, y consagrar su derecho a la autonomía". ' La moción tiene dos objetivos primordiales: por un lado, busca eliminar una serie de normas legales, principalmente contenidas en el Código Civil (en adelante CC), que establecen y regulan los efectos de la incapacidad absoluta para los 'dementes' y los 'sordos y sordomudos que no pueden darse a entender

\footnotetext{
${ }^{1}$ Congreso Nacional, "Proyecto de Ley: Modifica diversos textos legales con el objeto de eliminar la discriminación en contra de personas con discapacidad intelectual, cognitiva y psicosocial, y consagrar su derecho a la autonomía", Boletín $\mathrm{N}^{\circ} 12441-17,2019$, proyecto y estado de tramitación disponibles en línea: https://www.camara.cl/legislacion/ProyectosDeLey/tramitacion.aspx?prmID=12972
} 
claramente', lo que en la práctica significa una privación de la capacidad jurídica de ejercicio de derechos a un grupo de personas con discapacidad. Por otro lado, la moción busca modificar la Ley 20.422 (sobre igualdad de oportunidades e inclusión social de personas con discapacidad) con la finalidad de establecer las bases de un 'Sistema de Apoyos y Salvaguardas para el Ejercicio de la Personalidad Jurídica', lo que en la práctica vendría generar una forma de respetar la capacidad jurídica de ejercicio de aquellos temporal o permanentemente impedidos o restringidos en la exteriorización de su voluntad, preferencias o deseos.

La moción presentada supone un cambio de paradigma en relación con la comprensión de la capacidad jurídica de las personas. ${ }^{2}$ El presupuesto de la moción es que el cambio legal puede llevar a una transformación social en lo que respecta a su objeto y generar las condiciones para una sociedad más respetuosa de la autonomía de las personas con discapacidad mental (en adelante PDM). Para que ello suceda, el cambio legal debe ser sensible a dicha idea de transformación social y producir mediante su adopción una discusión legal y social de suficiente entidad al respecto. Un cambio legal acelerado corre el riesgo de fracasar. En una primera hipótesis, por no ser capaz de convencer de la necesidad de un cambio social al respecto a quienes toman las decisiones colectivas, $\mathrm{y}$ en ese sentido existen personas que creen de buena fe que la única manera de proteger los intereses de las PDM es a través de la práctica de la incapacitación. En una segunda hipótesis, por correr el riesgo de ser un cambio legal cosmético sin potencial de transformación social.

Este trabajo busca proponer ciertas ideas embrionarias con el fin de generar las condiciones para un análisis crítico del régimen de capacidad jurídica de las PDM en el sistema jurídico chileno desde una perspectiva de derechos humanos, y entender de esta manera el contexto y la discusión más general en que la moción mencionada se inserta. Si bien existen, como podremos ver, poderosas razones para legislar en la dirección y en los términos recogidos en la moción, las profundas modificaciones asociadas no anticipan una tramitación simple del proyecto legislativo. El presente trabajo, por tanto, busca contribuir al intenso y probablemente largo debate que se instalará en el Congreso, pero también en la academia y la sociedad,

\footnotetext{
${ }^{2}$ Por todos: BACH, Michael; Kerzner, Lana, "A new paradigm for protecting autonomy and the right to legal capacity”, Law Commission of Ontario, Ontario, 2014, 196 p., en línea: https://www.lco-cdo.org/ wp-content/uploads/2010/11/disabilities-commissioned-paper-bach-kerzner.pdf
} 
respecto al acceso al ejercicio de derechos por parte de las PDM, en particular aquellas que aquellas personas con discapacidad con mayores necesidades. Para ello, considero que es necesario partir mediante la identificación previa de las tensiones entre la regulación nacional y las obligaciones establecidas por los instrumentos respectivos del derecho internacional de los derechos humanos, en particular, de la Convención sobre los Derechos de las Personas con Discapacidad (en adelante, CDPD).

Esa tensión puede ser caracterizada como la necesidad de actualizar la legislación doméstica con un modelo de ejercicio de la capacidad jurídica que solucione adecuadamente la demanda de la CDPD por igual capacidad jurídica (que incluya no sólo el goce sino también el ejercicio de derechos), que satisfaga los apoyos que son necesarios para el ejercicio de dicha capacidad, y que, por último, considere las necesidades de cuidado que las personas con discapacidad experimentan en la medida de que son personas vulnerables, más susceptibles a abusos, maltratos o discriminación que el resto de la población. Si bien ambas categorías, apoyos y cuidados, son diferentes, ambas suponen formas de tratamiento de una persona que pueden ser vistas, desde una perspectiva tradicional, como incompatibles con su autonomía. Mientras los apoyos están recogidos por la CDPD y forman parte del modelo para el ejercicio de la capacidad jurídica propuesto por la Convención en su art. 12, el cuidado es un concepto más general que subyace a la CDPD (por ejemplo, se puede identificar su importancia en la justificación del art. 16 CDPD) y que está vinculado a la vulnerabilidad de las personas con discapacidad. Dado que la autonomía y el cuidado pueden entrar en conflicto, es necesario abordarlos de una manera cuidadosa. Ello es central para la efectividad de los derechos reconocidos por la CDPD, y especialmente para las PDM. Su adecuado tratamiento permitirá avanzar en la dirección correcta para poder satisfacer las promesas de la inclusión social y el respeto hacia estas personas. Asimismo, contribuiría a la eliminación de varias las formas de discriminación y estigmatización de las que estas personas son víctimas.

La estructura del presente trabajo es la siguiente: la primera sección introduce el problema a tratar, esto es, la abierta tensión entre el régimen de capacidad jurídica y ejercicio de derechos de la legislación nacional y las obligaciones que nacen de la CDPD. La segunda sección caracteriza dicha tensión en términos de la relación entre modelos de la discapacidad, presentados en términos de teoría social, y regímenes de atribución de la capacidad de ejercer derechos por el ordenamiento jurídico. Se describe 
la regulación chilena de atribución de capacidad jurídica por estatus vinculándola al modelo médico de la discapacidad, y se la enfrenta a la regulación de la CDPD que establecería un régimen de atribución universal vinculado al modelo social de la discapacidad. La tercera sección intenta mostrar algunos matices que, aunque sutiles llevan a repensar la simplicidad de la tarea que el Estado de Chile tiene por delante a la hora de cumplir con sus obligaciones internacionales. Se introduce la duda sobre cuáles son los márgenes con que las legislaciones nacionales cuentan para adecuarse a las demandas de la CDPD. En particular, se enfatiza que, al menos preliminarmente cuando se examina la literatura, no existiría una sola forma de implementar dichas demandas y que existen razonables desacuerdos a la hora de determinar qué tan radicalmente deben ser aceptadas. También en la sección tercera se plantea la necesaria cuestión acerca del fundamento teórico del cambio legal. Si bien las obligaciones internacionales de Chile pueden considerarse como el antecedente directo del cambio legislativo demandado, éste implica la necesidad de reconceptualizar ciertos fundamentos filosóficos acerca de la atribución de la personalidad legal en el derecho contemporáneo. Dicho de otro modo, el debate que se librará en Chile respecto a la moción presentada, no sólo se llevará a cabo en el nivel del derecho, sino de la comprensión social del significado de la autonomía y la discapacidad. Para ese propósito, se sugiere que el modelo social de la discapacidad no agota la cuestión de la teoría subyacente al cambio legal y se presentan tres líneas de teorización que podrían contribuir a darle más sólidos fundamentos. Finalmente, la cuarta sección del trabajo presenta tres áreas de ejercicio de derechos fundamentales en que una reforma como la presentada en la moción parlamentaria arriba mencionada impactaría. Se sugiere que un análisis pormenorizado del impacto del cambio de régimen de atribución de capacidad jurídica es necesario no sólo para su mayor efectividad sino también para evitar que dicha modificación legal impacte negativamente en las propias personas que se busca empoderar.

\section{LA TENSIÓN ENTRE DERECHO INTERNACIONAL Y DERECHO INTERNO}

El art. 12 de la CDPD sostiene el igual reconocimiento de las personas con discapacidad ante la ley, estableciendo el derecho al reconocimiento de la personalidad jurídica y la obligación de implementar un régimen de 
capacidad jurídica que sitúe a dichas personas en igualdad de condiciones con las demás en todos los aspectos de la vida. Junto con esto, dicho artículo señala que los Estados Parte de la CDPD incorporarán los apoyos que las personas con discapacidad necesiten para el ejercicio de su capacidad jurídica y así como las salvaguardas para proteger, entre otras cosas, el ejercicio de derechos, la voluntad y las preferencias de las personas con discapacidad frente a potenciales abusos. Este régimen de apoyos implica, por un lado, el reconocimiento de la libertad de decisión de las personas con discapacidad; $y$, por otro, un arreglo - que puede incluir la participación de un tercero, pero también puede constituir, por ejemplo, el reconocimiento de métodos de comunicación distintos y no convencionales - que tenga como finalidad facilitar el proceso de toma de decisiones y permitir el ejercicio de la capacidad jurídica. Por último, este artículo consagra, y así lo ha ratificado el Comité de Derechos de las Personas con Discapacidad (en adelante el Comité), ${ }^{3}$ el rechazo de la CDPD frente cualquier forma de regulación de la capacidad jurídica que discrimine a las personas afectadas por una discapacidad mental, exigiendo que la legislación doméstica de los Estados parte elimine las normas que se han traducido en prohibiciones de ejercicio autónomo de derechos.

En relación con nuestro sistema jurídico, esto implica, por un lado, la necesidad de revisar el régimen de incapacidad absoluta por demencia y el régimen de sustitución de voluntad mediante representación (guarda) consagrados en los arts. 338, 390, 456, 460, 1445 a 1447 del Código Civil, y reforzados por la Ley 18.600 (de deficientes mentales). Implica, asimismo, armonizar una serie de instituciones dispersas a través de nuestro sistema jurídico que implementan dicho régimen de incapacidad en varias esferas e impiden el ejercicio de derechos de forma autónoma por parte de las PDM. Ejemplo de estas últimas son, entre otros, el párrafo 8 de la Ley 20.584 (derechos del paciente) que limita la autonomía para decidir sobre tratamientos médicos irreversibles (como la esterilización) y autoriza la internación de ciertas personas en contra de su voluntad, o el art. 16 de la Constitución Política que suspende el derecho a sufragio de los interdictos por demencia. El Estado de Chile debe enfrentar la obligación contraída, que ha sido identificada como una tarea pendiente en la implementación

${ }^{3}$ Comité de las Naciones Unidas sobre los Derechos de las Personas con Discapacidad (Eds.), Observación General $N^{o} 1$ de 2014 del Comité sobre los Derechos de las Personas con Discapacidad de la Organización de Naciones Unidas, Naciones Unidas, s/1., 2014. 
de la CDPD en nuestro país, tanto por el propio Servicio Nacional de la Discapacidad, ${ }^{4}$ la Cámara de Diputados, ${ }^{5}$ el Instituto de Derechos Humanos ${ }^{6}$ y el Ministerio de Desarrollo Social, ${ }^{7}$ como por el Comité. ${ }^{8}$

La capacidad jurídica ha sido comprendida, desde el punto de vista del derecho civil, como una institución que permite garantizar que las persona que celebran actos jurídicos lo hagan con responsabilidad. ${ }^{9}$ De esa afirmación puede derivarse que la capacidad garantiza, por un lado, la estabilización de expectativas en el tráfico jurídico, y por otro, la protección de los intereses de sujetos considerados como especialmente vulnerables. Tomando en cuenta esas finalidades la idea de representación y sustitución de voluntad en ciertos casos es vista como decisión adecuada. Sin embargo, el régimen de capacidad jurídica, por tanto, el ejercicio de derechos no es sólo una cuestión que compete al derecho civil, sino que también compete y permite una mirada desde el punto de vista de los derechos humanos. Esto se debe a que un régimen de sustitución de voluntad insensible a los requerimientos de la CDPD constituye una violación flagrante del ya mencionado derecho al igual reconocimiento ante la ley. Sin embargo, los efectos que el régimen de sustitución de voluntad vigente en Chile tiene en el disfrute y ejercicio de los demás derechos humanos y constitucionales de las PDM son tremendamente importantes. ${ }^{10}$ No solo impactan en la invisibilización de la voluntad, los intereses y los planes de la PDM en el ejercicio de su derecho

\footnotetext{
${ }^{4}$ Servicio Nacional de la Discapacidad, Cuestionario a los Estados Partes de la Relatora Especial sobre los Derechos de las Personas con Discapacidad, SENADIS, Santiago, 2014.

${ }^{5}$ CÁmara de Diputados (Eds.), Evaluación de la Ley 18.600. Establece normas sobre discapacitados mentales, Departamento de Evaluación de la ley, Cámara de Diputados, Valparaíso, 2013, 75 pp. en línea: https://obtienearchivo.bcn.cl/obtienearchivo?id=documentos/10221.1/44459/1/informe_final_ ley_18600.pdf.

${ }^{6}$ Instituto Nacional de Derechos Humanos, Situación de los Derechos humanos en Chile, Informe Anual, INDH, Santiago, 2014, pp. 109-122, en línea: https://bibliotecadigital.indh.cl/ handle/123456789/740.

${ }^{7}$ Ministerio de Desarrollo Social, Informe de Desarrollo Social 2016, Gobierno de Chile, Santiago, 2016.

${ }^{8}$ Comité de las Naciones Unidas sobre los Derechos de las Personas con Discapacidad (Eds.), Observaciones finales sobre el informe inicial de Chile (CRPD/C/CHL/CO/1), Naciones Unidas, Nueva York, 2016, 10 pp., disponible en línea: https://acnudh.org/comite-sobre-los-derechos-de-las-personascon-discapacidad-crc/.

${ }^{9}$ Por todos, Lyon, Alberto, Personas Naturales, Ediciones Universidad Católica de Chile, Santiago, 2007.

${ }^{10}$ Por ejemplo, Bariffi, Francisco; Palacios, Agustina, Capacidad Jurídica y Discapacidad: México. Cuaderno de Trabajo n 12, Eds. FUTUEX (Fundación Tutelar de Extremadura), Bajadoz, 2009.
} 
consentir y expresar preferencias personales ante el sistema de salud, ${ }^{11}$ de su libertad personal frente a internaciones involuntarias, ${ }^{12}$ de su autonomía reproductiva, ${ }^{13} \mathrm{y}$ en el ejercicio de los derechos de participación política, ${ }^{14}$ sino que se extienden al disfrute de la mayoría de los derechos consagrados en la CDPD y en otros instrumentos de derechos humanos, como el derecho de administrar su relaciones patrimoniales, ${ }^{15}$ a la vida privada, ${ }^{16} \mathrm{a}$ formar una familia y a establecer y mantener relaciones afectivas, ${ }^{17}$ a vivir independientemente ${ }^{18}$ y a trabajar, ${ }^{19}$ entre otros. ${ }^{20}$

Existen muchas personas que se ven afectadas en mayor o menor medida, y en aspectos muy diferentes, por esta situación. Entre ellas, además de las PDM, sobresalen las personas que colaboran con y cuidan de las PDM. La decisión de modificarla y la modificación propuesta requiere tomar en cuenta dicha complejidad. Si bien este trabajo usa la expresión discapacidad mental, ${ }^{21}$ siguiendo la regulación nacional sobre la materia, como una categoría que engloba a personas con discapacidad tanto psíquica como intelectual, no olvida lo problemático de la terminología que rodea estos fenómenos y las sensibilidades que pueden ser heridas cuando ocupan generalizaciones que engloban fenómenos tan diversos. Esa diversidad sin duda debe considerarse cuando pensamos en regular sobre el régimen de capacidad jurídica. Por ejemplo, las personas con discapacidad intelectual congénita, como aquellos que presentan Síndrome de Down, requieren otro tipo de medidas y apoyos, y sus preocupaciones se refieren a aspectos diferentes, que las personas con discapacidad psíquica que son normalmente pacientes del sistema de salud mental como las personas esquizofrénicas $\mathrm{y}$,

${ }^{11}$ Art. 25 CDPD v. par. 8 Ley 20.584, 2012.

${ }^{12}$ Art. 14 CDPD v. art. 25 Ley 20.584, 2012, y art. 455 del Código Procesal Penal.

${ }^{13}$ Art. 23 CDPD v. art. 24 Ley 20.584, 2012.

${ }^{14}$ Art. 29 CDPD v. art. 16 de la Constitución Política de la República.

${ }^{15}$ Art. 12.5 CDPD v. art. 1682 CC

${ }^{16}$ Art. 22 CDPD

${ }^{17}$ Art. 23 CDPD v. art. 5 Ley 19.947, 2004, y art. 12 Ley 19.620, 1999.

${ }^{18}$ Art. 19 CDPD v. art. 9 Ley 18.600, 1987.

${ }^{19}$ Art. 27 CDPD v. art. 16 Ley 18.600, 1987.

${ }^{20} \mathrm{~V}$. para conocer más sobre estos aspectos, el proyecto desarrollado entre la Fundación Isabel Aninat y la Universidad de Chile, titulado Capacidad jurídica y discapacidad intelectual en Chile, proyecto orientado a la incidencia legislativa, de 2017.

${ }^{21}$ Asimismo, usa la expresión persona con discapacidad, por sobre otras como persona en situación de discapacidad, por ser el término jurídico reconocido tanto por el derecho internacional como por el derecho domestico chileno. 
a su vez, éstas requieren otras medidas que las personas con enfermedades degenerativas como la demencia y el Alzheimer, quienes, con el alza de la expectativa de vida, son cada vez más numerosas. Asimismo, quienes tienen a su cuidado a estas personas, ya sean miembros de su familia o trabajadores de instituciones estatales o instituciones privadas con o sin fines de lucro, son partes interesadas en la forma de adopción y el contenido de las decisiones de estas personas, siendo los candidatos naturales para asumir las labores de apoyo en la toma de decisiones. Su experiencia en el cuidado de las PDM podría ser considerablemente transformada y su rol y participación afectada por un cambio legislativo, y es sostenible pensar que su opinión debe asimismo ser tenida en cuenta en la determinación de dicho cambio legal, pese a que muchas veces ellas mismas son quienes vulneran los derechos de las PDM.

\section{LA CUESTIÓN DE LOS MODELOS DE DISCAPACIDAD}

El problema descrito en la sección anterior suele ser formulado como una pugna entre dos modelos conceptuales en torno a la discapacidad, el modelo médico y el modelo social. El modelo médico de la discapacidad puede ser vinculado a un régimen jurídico restringido de atribución de la capacidad para ejercer derechos. Por otro lado, el modelo social de la discapacidad, recogido por la regulación de la CDPD, apuntaría al establecimiento de un régimen de atribución universal de capacidad de ejercicio de derechos.

\section{El derecho chileno y el modelo médico}

El régimen jurídico chileno que regula la discapacidad ha avanzado hacia el establecimiento de un marco legal adecuado para el desarrollo progresivo de unas prácticas estatales respetuosas de los derechos de las personas con discapacidad. Además de la subscripción y ratificación de la CDPD, ${ }^{22}$ se han creado varios cuerpos legales tendientes a la inclusión de las personas con discapacidad, el más importante de los cuales es la Ley 20.422 (de igualdad de oportunidades e inclusión social de personas con

${ }^{22}$ El 29 de julio de 2008. 
discapacidad). ${ }^{23}$ No obstante este positivo avance, puede identificarse una resistencia del modelo médico de discapacidad a ser desplazado por el modelo social que inspira la CDPD, y esto es especialmente claro en la regulación de la discapacidad mental.

El modelo médico de la discapacidad, de larga vigencia en nuestro país, surgió a inicios del siglo XX, caracterizándose por abordar la discapacidad desde una perspectiva individual, es decir, centrando su objeto de análisis en la deficiencia asociada al individuo. Conceptualmente, bajo el prisma de este paradigma, las personas con discapacidad son consideradas como minusválidas, entendiendo por tales aquellas personas que como consecuencia de sus deficiencias ven reducidas sus posibilidades de integración y participación social. Las deficiencias, diagnosticadas medicamente como enfermedades, constituirán realidades modificables mediante el tratamiento médico, en virtud del cual la persona puede y debe ser rehabilitada. ${ }^{24}$ Para el modelo médico, la obligación de cuidado fundamental es la del tratamiento terapéutico que tiene como protagonista al sistema de salud, pero sobre todo a la propia persona discapacitada, quien es considerada como la principal responsable de su rehabilitación. ${ }^{25}$

La vigencia del modelo médico de discapacidad puede observarse en el texto de las leyes 18.600 y 20.584 antes citadas. Cuando miramos los arts. $2^{\circ}$ y $3^{\circ}$ de la Ley 18.600 nos encontramos con la consagración del modelo médico en el centro de la regulación nacional de la discapacidad mental. El primero considera la discapacidad mental como la "consecuencia de una o más limitaciones síquicas, congénitas o adquiridas, previsiblemente de carácter permanente y con independencia de la causa que las hubiera originado, vea obstaculizada, en a lo menos un tercio, su capacidad educativa, laboral o de integración social". El segundo de estos artículos determina que dicha medición se realizará mediante un instrumento validado por la Organización Mundial de la Salud. En concordancia con la definición de la Ley 18.600, la calificación y certificación de la discapacidad - regulada en el Decreto N47/2013 del Ministerio de Salud - continúa centrándose en la identificación de ciertos déficits cognitivos, comunicacionales o

\footnotetext{
${ }^{23}$ Véase también, art. 2, Ley 20.609, 2012; art. 61, Ley 18.700, 1988; y Ley 21.015, 2017.

${ }^{24}$ Véase, por ejemplo, Palacios, Agustina, El modelo social de discapacidad: orígenes, caracterización y plasmación en la Convención Internacional de los Derechos de las Personas con Discapacidad, CINCA, Madrid, 2008.

${ }^{25}$ Barnes, Colin; Mercer, Geof, Exploring Disability, Polity Press, Cambridge, 2010, capítulo 3.
} 
intelectuales de la persona con discapacidad, y no en las distintas barreras de origen social que la afectan.

El rasgo más importante de la pervivencia del modelo médico en nuestro país es, sin embargo, que nuestro ordenamiento civil mantiene vigente un régimen de sustitución de voluntad para ciertas PDM, basado en una declaratoria de incapacidad mediante un procedimiento de interdicción judicial ${ }^{26} \mathrm{O}$ meramente administrativo, ${ }^{27}$ conforme a los cuales el diagnóstico socio/médico de la persona prevalece sobre cualquier otra consideración..$^{28}$ Este rasgo de nuestro derecho se corresponde con lo que teóricamente se ha denominado un modelo de asignación de capacidad jurídica por estatus, que asume que la discapacidad mental de una persona, médicamente diagnosticada, implica una falta de capacidad jurídica. Este modelo descansa en dos premisas: en primer lugar, parte de una visión binaria de la capacidad mental conforme a la cual uno puede tener o no tener capacidad mental; ${ }^{29}$ $\mathrm{y}$, en segundo lugar, que una vez que una persona es considerada capaz mentalmente, a ella se le concede una amplia libertad para realizar acciones que pueden resultar en un inevitable daño a sus intereses. Por el contrario, esa libertad es denegada a aquellos considerados como discapacitados mentales, respecto de quienes la sociedad actúa paternalistamente. ${ }^{30}$ Existe un amplio consenso en la literatura especializada en sostener que el modelo de estatus es incompatible con un régimen de apoyos y salvaguardas como

${ }^{26}$ Arts. 456 y ss. CC, arts. 838 y ss. del Código de Procedimiento Civil, y art. 4 Ley 18.600, 1987.

${ }^{27}$ Art. 18 bis, Ley 18.600, 1987.

${ }^{28}$ Véase, por ejemplo, Corte de Apelaciones de Santiago, 30 de mayo de 2016, Rol Civil 1304-2016:

"Que, de esta forma, aparecen satisfechas todas las exigencias que contempla el legislador para efectuar la declaración a que se refiere el inciso segundo de la norma citada en el motivo primero. Ahora bien, la impresión que el juez de la causa se forme respecto del estado de salud mental de la persona con discapacidad cuya declaración de interdicción se solicita, con motivo de la realización de la audiencia que prevé la ley, no puede sustituir el dictamen emitido por quienes profesan la ciencia de la medicina y que se desempeñan, precisamente, en el área de la salud mental, únicas personas que se encuentran profesionalmente capacitadas para proporcionar un diagnóstico de esa especificidad técnica. Lo anterior no importa que la audiencia referida sea superflua ni que el rol del juez en procedimientos de esta naturaleza sea irrelevante, sino únicamente que, en el evento de optarse por esta vía para obtener se decrete la interdicción por demencia de una persona y no por el pleito contencioso, el tribunal deberá limitarse constatar el cumplimiento de las exigencias legales sobre la base de los antecedentes que se le hagan valer y efectuar las declaraciones que corresponda (considerando $3^{\circ}$ )".

${ }^{29}$ Quinn, Gerard, "Personhood and Legal Capacity Perspectives on the Paradigm Shift of Article 12 CRPD", HPOD Conference Harvard Law School, 20 de febrero de 2010, p. 12.

${ }^{30}$ Quinn, Gerard; Arstein-LersLaKe, Anna, "Restoring the Human in Human Rights-Personhood and Doctrinal Innovation in the UN Disability Convention", en: Douzinas, C., GearTy, C. (Eds.), The Cambridge companion to human rights law, Cambridge University Press, Cambridge, 2012, p. 41. 
el previsto en el art. 12 CDPD en la medida que el apoyo allí previsto no podría cambiar el estatus de discapacidad y, por tanto, de incapacidad legal. ${ }^{31}$

\section{La Convención y el modelo social}

El tratamiento legal del que son objeto las PDM en Chile contrasta con la transformación que durante las últimas dos décadas ha afectado a la comprensión de la discapacidad en general y la discapacidad mental en particular en la literatura especializada. ${ }^{32}$ Aquella ha comenzado a dejar de ser vista sólo como un problema médico que requiere tratamiento de este tipo y ha comenzado a ser vista como un problema primariamente de derechos humanos que, partiendo de la base de la igual dignidad de todas las personas mira a la discapacidad como un conjunto de obstáculos físicos y actitudinales que deben ser removidos para la plena integración de las PDM en la sociedad. ${ }^{33}$ Así, en respuesta al enfoque médico-rehabilitador, surge en los años setenta el modelo social de la discapacidad. Este paradigma pretende poner de relieve que los orígenes de la discapacidad están mucho más relacionados con factores sociales que con la deficiencia individual. De ahí que la discapacidad constituya, en definitiva, un fenómeno específico de opresión, mediante el cual las personas que no satisfacen un estándar de normalidad son sistemáticamente excluidas de la vida social. En consonancia, lo que debe rehabilitarse no es la persona, sino la intolerancia de la sociedad a aceptar las diferencias funcionales de las PD. ${ }^{34}$ Desde el punto de vista del modelo social, la obligación de cuidado se traspasa del sistema de salud al Estado, el que debe regular la interacción entre la sociedad y las PD de una manera que sea respetuosa con la diversidad funcional de estas últimas, y la responsabilidad de la

\footnotetext{
${ }^{31}$ Por todos: Browning, Michelle; Bigby, Christine; Douglas, Jacinta, "Supported decision making: Understanding how its conceptual link to legal capacity is influencing the development of practice", Research and Practice in Intellectual and Developmental Disabilities, 2014, 1 (1), p. 38.

${ }_{32}$ Por ejemplo, BARIFFI, Francisco, El régimen jurídico internacional de la capacidad jurídica de las personas con discapacidad, CERMI, España, 2016; SHAKESPEARE, Tom, "The social model of disability", en: Davis, Lennard (ed.), The disability studies reader, Taylor \& Francis, Abingdon, 2006.

${ }^{33}$ Por ejemplo, Perlin, Michael, "A Change is Gonna Come: The Implications of the CRPD for the Domestic Practice of Constitutional Mental Disability Law", Northern Illinois University Law Review, 2008, 29 (3); Figueroa, Miguel Ángel; Inostroza, Hernán, Discapacidad y Salud Mental: una visión desde el SENADIS, Alvimpress, Santiago, 2016.

${ }^{34}$ Por todos, Oliver, Michael; Bochel, Hugh, "The politics of disablement", International Journal of Rehabilitation Research, 1991, 14 (2).
} 
eliminación de las consecuencias negativas es también desplazada desde la PD hacia su contexto social.

El modelo social influyó decisivamente en el diseño de la CDPD y continúa influyendo en su supervisión e implementación. La discapacidad está definida en su art. $1^{\circ}$ como aquella que afecta a personas con "deficiencias físicas, mentales, intelectuales o sensoriales a largo plazo que, al interactuar con diversas barreras, puedan impedir su participación plena y efectiva en la sociedad, en igualdad de condiciones con los demás". Similar definición hace la Ley 20.422, que busca implementar la CDPD en nuestro país. Ambos textos consagran una definición que se corresponde con el modelo social y que mediante la distinción entre deficiencia (impairment) y discapacidad (disability), vincula esta última al contexto social que interactúa con la deficiencia como la principal causa de la discapacidad y, por tanto, se la disocia al menos parcialmente de las características individuales del sujeto.

En sintonía con el modelo social, el art. 12 de la Convención establece una obligación de reconocer la capacidad jurídica en términos iguales y de proveer apoyos para la toma de decisiones y salvaguardas para la prevención de abusos. Esta obligación ha sido entendida por una parte importante de la literatura como la exigencia de implementar un modelo universal de capacidad jurídica, que mira a ésta como un atributo universal, que debe separarse de la capacidad mental del individuo (como consideración fáctica) y en particular de su capacidad para tomar decisiones. ${ }^{35}$ Refleja, en cambio, un derecho del individuo (una consideración normativa) a tomar decisiones que le afectan y a que dichas decisiones sean respetadas. ${ }^{36}$ En armonía con el modelo social, la capacidad jurídica y mental de una persona no son definidas en términos de su discapacidad, sino que el foco está puesto en factores sociales y contextuales que impactan negativamente en su posibilidad de tomar decisiones. ${ }^{37}$ El compromiso del modelo universal con un sistema de apoyos y salvaguardias se expresa en que, mediante estos mecanismos se permitiría entregar a todas las personas (y esa universalidad es probablemente su aspecto más polémico) las herramientas para realizar sus capacidades en la máxima medida posible mediante la eliminación de las

\footnotetext{
${ }^{35}$ Por ejemplo, BARIFFI, cit. (n. 32); BACH, Michael, "El derecho a la capacidad jurídica en la Convención de la ONU sobre los derechos de las personas con discapacidad", en BARIFFI, F., Palacios, A. (Coords.), Capacidad jurídica, discapacidad y derechos humanos, Editorial EDIAR, Buenos Aires, 2011; QuINN, cit. (n. 29).

${ }^{36}$ BACH y KerZner, cit. (n. 2), p. 18.

${ }^{37}$ ShaKespeare, cit. (n. 32).
} 
barreras que perjudican las posibilidades de las PDM de expresar su voluntad y perseguir sus intereses. ${ }^{38}$ Por ejemplo, el modelo de apoyos desarrollado por Bach involucra diferentes tipos de apoyo para distintos requerimientos, incluyendo lo que él denomina 'facilitación' que comprende el apoyo a personas respecto de las cuales nadie puede "razonablemente determinar su voluntad o intención y describírsela a alguien más", ${ }^{39}$ intentando implementar la promesa del modelo universal de capacidad jurídica en toda su extensión.

\section{ENFOQUES TEÓRICOS Y DERECHO COMPARADO}

Como puede concluirse de la sección anterior, el problema normativo entre el derecho nacional y el derecho internacional en lo relativo a la capacidad de ejercer derechos puede ser presentado como uno entre dos comprensiones o modelos de la discapacidad (médico y social), ${ }^{40}$ y con dos regímenes de atribución de la capacidad jurídica y el ejercicio de derechos que corresponde a las PDM que se seguirían de esos dos modelos (por estatus y universal). ${ }^{41}$

Esta sección quiere llamar la atención acerca de lo simplista de esta forma de retratar el problema e identificar dos ámbitos a los que se puede dirigir el estudio académico de la cuestión del ejercicio de derechos por parte de las PDM. Por un lado, el debate puede enriquecerse al tomar en cuenta otras perspectivas teóricas distintas del modelo social de la discapacidad, que amplían el horizonte de referencia respecto de la dicotomía modelo médico/ modelo social. Por otro lado, la discusión también podría enriquecerse si se presta atención a la construcción de regímenes intermedios o matizados de atribución de capacidad jurídica, sensibles no sólo a las demandas de autonomía, sino también a las necesidades de cuidado de las PDM, tomando en cuenta la tremenda discusión académica, política y social que el art. 12

\footnotetext{
${ }^{38}$ Quinn y Arstein-Lerslake, cit. (n. 30).

${ }^{39}$ BACH y KerZner, cit. (n. 2), p. 163.

${ }^{40} \mathrm{Si}$ bien el modelo social ha tenido cabida en el derecho nacional a través de la regulación de la Ley 20.422 .

${ }^{41}$ Para una visión sintética, véase, BenAvides, Álvaro, "Capacidad jurídica: una reflexión necesaria a la luz de la Convención sobre los Derechos de las Personas con Discapacidad", Anuario de Derechos Humanos UDP, 2015, $\mathrm{N}^{\circ} 11$, pp. 39-56. Para un análisis detallado y sin lugar a dudas el mayor esfuerzo de abordaje en la doctrina nacional véase, Silva, Paula, La capacidad jurídica de las personas con discapacidad intelectual, Thomson Reuters, Santiago, 2017.
} 
de la CDPD ha generado desde su adopción. En este sentido, se invita a considerar alternativas ajenas a la dicotomía régimen por estatus/régimen universal.

Debe advertirse que el invitar a discutir sobre las cuestiones teóricas que rodean la atribución de capacidad jurídica a las PDM y de sus concreciones prácticas y legales, no busca desviar la atención de la urgencia de contar con una regulación más respetuosa de los derechos humanos de estas personas que, como ya se señaló en la primera sección, se encuentran afectados por la actual legislación. Se busca, por el contrario, que los pasos que se tomen en dirección a la protección de dichos derechos, sean parte de una solución transformadora de la posición que dichas personas detentan en una sociedad que sistemáticamente las discrimina, les priva de los medios para satisfacer sus necesidades básicas y, más importante para el trabajo que aquí se pretende, las priva de ejercer sus derechos básicos como seres humanos.

\section{Otras perspectivas teóricas a las que prestar atención}

Pese a que la CDPD ha recibido una influencia importante del modelo social de discapacidad, existen varios enfoques teóricos que podrían guiar la implementación de un régimen jurídico respetuoso de los derechos de las PDM. Considerar alternativas es urgente en la medida que la literatura especializada reconoce que una de las principales críticas al modelo social de la discapacidad viene justamente implicada por su debilidad para hacerse cargo de los problemas específicos que afectan a este grupo o grupos de personas con discapacidad..$^{42}$ En este sentido, debería tomarse en cuenta una importante literatura de reciente data que ha venido reflexionando teóricamente sobre la situación de las PDM, ya sea desde la filosofía política, ${ }^{43}$

\footnotetext{
${ }^{42}$ Por todos, Barnes y Mercer, cit. (n. 25), p. 69.

${ }^{43}$ Veáse, por ejemplo, BECKETt, Angharad, Citizenship and vulnerability: Disability and issues of social and political engagement, Palgrave Macmillan, Londres, 2006; PотнIER, Dianne; Devuin, Richard, Critical disability theory: Essays in philosophy, politics, policy, and law, UBC press, Vancouver, 2006; Kristiansen, Kristjana; Vehmas, Simo; ShaKespeare, Tom (Eds.), Arguing about disability: Philosophical perspectives, Routledge, London, 2008; CAREY, Allison, On the margins of citizenship, Temple University Press, Philadelphia, 2009; CAREY, Allison, "The Capacity Contract: Intellectual Disability and the Question of Citizenship", Disability Studies Quarterly, 2015, 35 (4); Tremain, Shelley, Foucault and the Government of Disability, University of Michigan Press, Ann Arbor, 2015.
} 
la filosofía moral, ${ }^{44}$ la teoría del derecho ${ }^{45}$ y el nuevo campo disciplinario de los estudios de la discapacidad, ${ }^{46}$ más vinculados con la teoría social. En dicha búsqueda de alternativas, sin embargo, debería darse preeminencia a aquella literatura que adopta enfoques que justifican la potencialidad de realización de todo ser humano, la interrelación social como fundamento del reconocimiento de autonomía, y la dependencia, vulnerabilidad y necesidad de cuidado como elementos necesarios de la debida consideración de vida humana. Así, sólo de forma exploratoria se pueden identificar tres enfoques teóricos que podrían iluminar las alternativas y esclarecer las bases conceptuales que requiere una reforma tan importante al régimen de capacidad jurídica y su garantía en un régimen de cuidado adecuado.

En primer lugar, la perspectiva del reconocimiento, representada por autores como FRASER ${ }^{47}$ y HONNETH, ${ }^{48}$ puede servir para aproximarse a la idea la inclusión de las PDM como personas igualmente valiosas para la sociedad. Esto se debe, en gran parte, al énfasis de la perspectiva del reconocimiento en afirmar que la autonomía es fruto de cierto tipo de interrelación social conforme a la que personas entre si se reconocen mutuamente con ciertas cualidades valiosas. La idea del reconocimiento implica la necesidad de conformación de instituciones que posibiliten a la sociedad asegurar las condiciones bajo las cuales ese reconocimiento mutuo es posible. Sólo para considerar uno de los autores de esta línea de pensamiento, HoNNETH distingue tres esferas de reconocimiento (amor, respeto legal y estima social) en las cuales las personas pueden desarrollar relaciones de reconocimiento (conforme a los principios de necesidad, igualdad y contribución), y a su vez, contribuir a afirmar las bases de la identidad, la autonomía individual y de un bienestar humano basado en la auto-realización. En relación con las PDM, el enfoque del reconocimiento invierte la tradicional relación entre autonomía y personalidad. Mientras las teorías liberales de la personalidad

\footnotetext{
${ }^{44}$ Veáse, por ejemplo, Kittay, Eva; Feder, Ellen, The Subject of Care: Feminist Perspectives on Dependency, Rowman \& Littlefield, Maryland, 2003; Kittay, Eva; CARLson, Licia, Cognitive disability and its challenge to moral philosophy, John Wiley \& Sons, New Jersey, 2010.

${ }^{45}$ Veáse, por ejemplo, Minow, Martha, Making All the Difference. Inclusion, exclusion and American law, Cornell University Press, New York, 1990; Fineman, Martha, The Autonomy Myth A Theory of Dependency, The New Press, New York, 2004.

${ }^{46}$ Veáse, por ejemplo, Davis, cit. (n. 32).

${ }^{47}$ Fraser, Nancy; Honneth, Axel, Redistribution or recognition? A political-philosophical exchange, Verso, New York, 2003.

${ }^{48}$ Honneth, Axel, The struggle for recognition: The moral grammar of social conflicts, The MIT Press, Massachusetts, 1995.
} 
tienden a reconocer personalidad a quienes son capaces de demostrar autonomía, la aproximación de HoNNETH considera que la autonomía de la cual todos somos potenciales titulares se consolida por su reconocimiento a través del amor, el respeto legal y la estima social. Una autonomía limitada en este sentido, puede ser la consecuencia de una falla en esas relaciones de reconocimiento. Por ejemplo, siguiendo de cerca la propuesta de HonNETH, INHAHEIMO argumenta que la falta de actitudes de reconocimiento frente a PDM constituye el caso más claro de exclusión social del presente, en la medida que se priva a dichos seres humanos de la posibilidad de desarrollar aspectos valiosos su personalidad. ${ }^{49}$ Que una persona sea considerada incompetente para tomar sus propias decisiones puede contribuir a consolidar la idea de que los eventos de su vida están fuera de su control y eso puede tener un efecto negativo en su autoestima y su comportamiento subsecuente. ${ }^{50}$ Por otro lado, también siguiendo a HonNeTH, WARren afirma que el reconocimiento es la perspectiva teórica más adecuada para abordar cuestiones fundamentales para considerar a las PDM como libres e iguales, esto es: primero, abordar la cuestión de su deficiencia individual y las necesidades de cuidado que esta deficiencia demanda; segundo, la exclusión social y política que estas personas experimentan; y, tercero, la estigmatización de la cual son víctimas. ${ }^{51}$

Un segundo enfoque teórico que se considera pertinente para este estudio es el enfoque de las capacidades, formulado por $\mathrm{SEN}^{52}$ y desarrollado con cierta profundidad teórica por Nussbaum. ${ }^{53}$ Este enfoque defiende una organización social que atribuye incondicionalmente ciertos derechos básicos con el carácter de capacidades que permiten todas las personas realizar ciertas funciones objetivamente valiosas. Conforme a este enfoque, se requiere que cada ser humano tenga una oportunidad de vivir una vida digna en el contexto de su diversidad y ello se logra permitiéndole alcanzar

${ }^{49}$ INHAHEIMO, Heikki, "Personhood and the social inclusion of people with disabilities: a recognitiontheoretical approach", en Kristiansen, Kristjana; Vehmas, Simo; Shakespeare, Tom (Eds.), Arguing about disability: Philosophical perspectives, Routledge, London, 2008.

${ }^{50}$ Dhanda, Amita, "Legal capacity in the disability rights convention: stranglehold of the past or lodestar for the future", Syracuse J. Int'l L. \& Com., 2007, vol. 34.

${ }^{51}$ WARrEN, Kacey Brooke, Recognizing justice for citizens with cognitive disabilities, Lexington Books, Maryland, 2015.

${ }^{52}$ Sen, Amartya, "The place of capability in a theory of justice", en Brighouse, H.; Robeyns, I. (Eds.), Measuring justice: primary goods and capabilities, Cambridge University Press, Cambridge, 2010.

${ }^{53}$ Nussbaum, Martha, Creating capabilities, Harvard University Press, Massachusatts, 2011; NussBaum, Martha, Las mujeres y el desarrollo humano, Herder Editorial, Barcelona, 2012. 
su máximo potencial en el ejercicio de sus capacidades. En estos términos, el enfoque de las capacidades se centra (al igual que el enfoque de derechos que es preeminente en el discurso de los derechos humanos) en la posibilidad del logro de ciertos resultados (disfrute de derechos básicos) más que en generar condiciones institucionales que posibilitarían una sociedad justa, que ha sido el énfasis de las teorías políticas liberales. ${ }^{54}$ Para este enfoque, la habilidad de los individuos de utilizar/transformar los recursos de los que disponen para disfrutar de ciertos derechos básicos aparece como fundamental. NussBaum ha desarrollado ciertos rasgos de su enfoque de las capacidades en relación con la situación de las PDM, afirmando: (1) que la racionalidad es solo un aspecto del valor de nuestra existencia y que una concepción adecuada de la justicia requiere incorporar aspectos materiales y emocionales de la experiencia humana; (2) que el respeto a la diversidad humana implica una necesidad de cuidado más profunda en el caso de las PDM, en la medida que éstas tienen más dificultades para convertir recursos en derechos básicos; y (3) que existe la necesidad de representación o sustitución de la voluntad para quienes no demuestran la habilidad para alcanzar el desarrollo necesario para ejercer ciertas funciones autónomamente, como sería el caso de PDM severa. ${ }^{55}$ Nos encontramos, por tanto, con una perspectiva teórica sumamente influyente en el nivel de la justificación del enfoque de derechos humanos, que estaría dispuesta a postergar la extensión de capacidad jurídica a ciertas PDM.

El tercer enfoque que aquí se identifica es la denominada ética del cuidado que, desde su desarrollo en el pensamiento feminista, ${ }^{56}$ ha intentado enfatizar las situaciones de dependencia que experimentan los seres humanos y las necesidades de cuidado que son correlativas a ellas. Esta aproximación busca poner atención en la particularidad de dichas necesidades de cuidado, sugiriendo abandonar la utilización de principios universales que puedan justificar derechos y prerrogativas para todas las personas por igual, para enfocarse, en cambio, en que el cuidado necesita cierto conocimiento específico acerca de las personas y sus necesidades. Así, la ética del cuidado prioriza un enfoque relacional y enfatiza el principio de la necesidad y sus

\footnotetext{
${ }^{54}$ Rawls, John, Una teoría de la justicia, Fondo de Cultura Económica, Santiago, 2012.

${ }^{55}$ Nussbaum, Martha, Las fronteras de la justicia: consideraciones sobre la exclusión, Paidós, Barcelona, 2006.

${ }^{56}$ Gilligan, Carol, In a different voice, Harvard University Press, Massachusetts, 1982.
} 
obligaciones correlativas en el contexto de relaciones sociales concretas. ${ }^{57}$ Mientras el centro de la preocupación de la ética del cuidado ha sido las relaciones de dependencia en general, el caso de las PDM ha sido adecuadamente abordado por autoras como Rogers, ${ }^{58}$ FINEMAN $^{59}$ y KITTAY. ${ }^{60}$ En particular, el trabajo de esta última sirve para explicar cómo el enfoque relacional puede determinar el grado de autonomía de cualquier individuo, ya sea el destinatario del cuidado o quien realiza la tarea de cuidado (quienes muchas veces están sujetos, por esa razón, a una desventaja estructural en términos de justicia social) considerando la distribución de cargas y beneficios en un contexto social dado. La inevitabilidad de la dependencia, que se expresa en el hecho de que todos en algún momento de nuestras vidas vamos a estar en una posición de vulnerabilidad y que requerirá de cuidados, sirve a KitTAY para argumentar que el orden social debe reconocer esta situación, admitiendo que todos cuidamos y somos cuidados, y compartimos preocupaciones que determinan nuestra condición humana, y en ese sentido, la posición en la que se encuentran las PDM no es categorialmente diferente a las de las demás personas.

Tanto el cuerpo teórico recién mencionado como las particularidades del caso de las PDM enfatizan la relación de mutua dependencia que hay entre las nociones de autonomía, por un lado, y apoyos y cuidado, por otro, y cuestionan la noción de autonomía tradicionalmente afirmada por el pensamiento liberal de inspiración kantiana. ${ }^{61}$ En este sentido, la demanda de que la capacidad jurídica de ejercicio sea atribuida a PDM tradicionalmente excluidas de ella, supone cuestionar y repensar una de las premisas fundamentales de la organización social y jurídica moderna: el condicionamiento de la capacidad jurídica al ejercicio de poderes de deliberación racional, entendidos como el poder de determinar un plan de vida como valioso y tomar las decisiones para perseguirlo, comprendiendo las consecuencias que de ellas se siguen. La idea de que quienes presentan

\footnotetext{
${ }^{57}$ Held, Virginia, The Ethics of Care: Personal, Political, and Global, Oxford University Press, Oxford, 2006; Kittay y Feder, cit. (n. 44); Sevenhuissen, Selma, Citizenship and the ethics of care, Psychology Press, New York, 1998.

${ }^{58}$ Rogers, Chrissie, Intellectual Disability and Being Human: A Care Ethics Model, Routledge, London, 2016.

${ }^{59}$ Fineman, cit. (n. 45).

${ }^{60}$ Kittay, Eva, Love's Labor: Essays on Women, Equality, and Dependency, Routledge, London, 1999; Kittay y Feder, cit. (n. 44).

${ }^{61}$ Rawls, cit. (n. 54), pp. 236 y ss.
} 
una carencia de este poder de deliberación, o al menos dan razones para dudar de su posesión en la medida que no son capaces de realizar y comunicar claramente sus decisiones, sean apoyados con la finalidad de que puedan expresar sus preferencias, intereses y puedan tomar las decisiones que los afecten supone un cambio radical en la forma de entender la autonomía, y su relación con la idea del cuidado que como sociedad debemos procurar a estas personas. ${ }^{62}$ Este cuestionamiento pone énfasis en la importancia que tiene, no solo para las PDM sino para las personas que se relacionan con ellas, y para las personas en general, la satisfacción de ciertas necesidades de cuidados, que deben ser provistos por terceras personas, como una condición del ejercicio de la autonomía. El énfasis de la CDPD en la provisión de apoyos para la toma de decisiones es la forma más evidente en que dichos cuidados pueden ponerse al servicio de la autonomía. Sin embargo, la vulnerabilidad, expresada por ejemplo en el texto del art. $16 \mathrm{CDPD}$, que requiere de una protección contra la explotación, la violencia y el abuso que dichas personas experimentan, demanda que sus necesidades de cuidado sean pensadas de una manera aún más general.

\section{Regímenes intermedios o matizados de atribución de capacidad}

Si la única interpretación posible del art. 12 CDPD es aquella que establece una obligación de contar con un régimen de apoyos y salvaguardas, y un modelo universal de capacidad, el problema jurídico que presenta a las jurisdicciones nacionales sería considerablemente más simple de lo que realmente es. Pero no es casual que el art. 12 haya sido indicado como un cambio de paradigma en el tratamiento de la discapacidad dado que sus implicancias son muy importantes y complejas. ${ }^{63}$ Es por esa misma razón que, tanto durante su discusión como después de acordada la versión final del artículo, surgieron voces que consideraban que el hecho de que no se estableciera la posibilidad de declaración de incapacidad y régimen de guarda para ciertos casos era una cuestión riesgosa. Dichas consideraciones llevaron a que algunos países formularan declaraciones interpretativas y reservas sobre el art. 12, en la medida que no estaban dispuestos a obligarse a cumplir una disposición de tan (deliberada) ambigüedad respecto a la

\footnotetext{
${ }^{62}$ Quinn \& Arstein-Lerslake, cit. (n. 30), p. 41.

${ }^{63}$ QuinN, cit. (n. 29).
} 
regulación de la capacidad de ejercicio que consagraba. ${ }^{64}$

La ambigüedad fue zanjada por la interpretación que el propio Comité realizó años más tarde en su primera Observación General del 2014, donde afirmó que el art. 12 excluye la subsistencia de un régimen de sustitución de voluntad, aunque sea excepcional. Asimismo, afirmó (a) que el derecho a la capacidad legal, en cuanto derecho civil, demandaba realización inmediata, esto es, no estaba sujeto al régimen de efectividad progresiva establecido en el art. $4^{\circ}$ para otros derechos de la CDPD, y (b) que los apoyos para la toma de decisiones eran algo diferente a los ajustes razonables y, por tanto, no eran susceptibles de ser limitados por constituir una carga desproporcionada o indebida, conforme al art. $2^{\circ}$ de la CDPD.

En abierto contraste con la posición que el Comité tomó, Australia declaró en su ratificación de la CDPD que lo hacía bajo el entendido que la Convención permitía un régimen de sustitución de voluntad que autoriza que una decisión pueda ser tomada en representación de una persona, si bien este último caso fue calificado, señalándose que únicamente procedería cuando existiera una necesidad, este fuera el último recurso disponible y quedara sujeto a salvaguardas. Similares declaraciones o reservas fueron realizadas por otros países como Canadá, Holanda, Noruega, Polonia y el Reino Unido, siendo este último un caso interesante porque su reserva fue retirada después de la entrada en vigencia de la CDPD, por considerar que su régimen de capacidad, que contempla casos de sustitución de voluntad, y por tanto, no puede catalogarse como un régimen de atribución universal, no infringía los términos del art. 12.

Como puede verse, el hecho de que el art. 12 establezca un modelo de capacidad universal es una cuestión discutida por la comunidad internacional y esta discrepancia, por un lado, abre la discusión sobre la posibilidad de entender el mandato de la CDPD en términos compatibles con otros modelos de reconocimiento de la capacidad jurídica de las PDM diferentes del régimen de capacidad universal. Por otro lado, de manera más general muestra que hay buenas razones para considerar regímenes alternativos al régimen demandado por el Comité. Es por eso que, frente a dichas reservas y declaraciones, y ante la tímida respuesta que la obligación del establecimiento de un régimen de capacidad universal ha tenido en el horizonte comparado, en que los casos de verdadera eliminación del

${ }^{64}$ Dhanda, cit. (n. 50). 
régimen de sustitución de voluntad son difíciles de encontrar, ${ }^{65}$ han surgido propuestas alternativas para entender el compromiso de la CDPD con el régimen de apoyos y salvaguardas.

Una de estas propuestas es un modelo escalonado (stepped approach) de capacidad que abandona el énfasis del modelo universal de un respeto igualmente distribuido y se enfoca, como el modelo de estatus, en la práctica de la toma de decisiones por parte de las PDM. Se diferencia de este último en que enfatiza que la capacidad de las PDM para actuar dentro de un determinado sistema jurídico no es estática, sino que cambia con el tiempo y de acuerdo con factores ambientales y de experiencia personal. ${ }^{66}$ La capacidad para tomar decisiones puede no ser la misma para diferentes áreas de la vida y para las distintas discapacidades que se engloban bajo el concepto de discapacidad mental. De esta manera, existe la necesidad de determinar un estándar de capacidad de ejercicio conforme el cual algunas personas no van a ser consideradas capaces de tomar decisiones incluso cuando actúen con apoyos, lo que requiere enfatizar la importancia de la evaluación de la capacidad de las PDM para tomar decisiones. Esto, sin embargo, permite separar la capacidad jurídica de las personas de su estatus de persona con discapacidad mental, y vinculando la primera a la capacidad de tomar decisiones, para lo cual se deben considerar una multiplicidad de factores. Como puede verse, un modelo escalonado evita la discriminación $a$ priori de un modelo de capacidad por estatus, pero garantiza las prerrogativas de los Estados a mantener el régimen de capacidad jurídica vinculado a la habilidad de tomar decisiones.

El modelo escalonado que se acaba de identificar es sólo uno de los regímenes alternativos al de capacidad universal. Identificar y estudiar esta clase de propuestas alternativas es una tarea de gran importancia a la hora de deliberar sobre la adopción de un régimen que se adecue a las necesidades de las PDM en nuestro país considerando la evidencia disponible y el desarrollo teórico y jurídico sobre la materia. En definitiva, el examen del derecho comparado, especialmente de aquellos países que se han tomado en serio sus obligaciones internacionales y que tienen una larga tradición de políticas públicas que consideran a las PDM, podría sugerir, y esa es justamente una

\footnotetext{
${ }^{65}$ Fallon-Kund, Marie; BickenbachB, Jerome, "New Legal Capacity Laws and the United Nations Convention on the Rights of Persons with Disabilities: An Overview of Five Countries in Europe", European Journal of Health Law, 2017, 24 (3).

${ }^{66}$ Browning, Bigby y Douglas, cit. (n. 31), p. 40.
} 
de las cosas que deben ser investigadas con detalle, que la CDPD permite la existencia de diversidad de regímenes de atribución de capacidad. Esas alternativas deben ser estudiadas cuidadosamente. No es trivial que la proliferación de modelos alternativos haya marcado y siga marcando la discusión sobre la forma en que debe interpretarse la obligación del art. 12 de prestar apoyos a la toma de decisiones en diferentes países. Esto ha ido produciendo una literatura creciente en Australia, ${ }^{67}$ España, ${ }^{68}$ Canadá, ${ }^{69}$ el Reino Unido ${ }^{70}$ y en los sistemas regionales de protección de derechos, especialmente por parte de la Corte Europea de Derechos Humanos ${ }^{71}$ y la supervigilancia de la Convención Interamericana para la Eliminación de todas las formas de Discriminación contra las Personas con Discapacidad ${ }^{72}$ bajo la supervisión del Comité del mismo nombre. Es importante señalar que

\footnotetext{
${ }^{67}$ Por ejemplo, Browning, BigBy y Douglas, cit. (n. 31); Gooding, Piers, "Supported decision-making: a rights-based disability concept and its implications for mental health law". Psychiatry, Psychology and Law, 2013, 20 (3).

${ }^{68}$ Por ejemplo, DinERSTEIN, Robert, "Implementing legal capacity under Article 12 of the UN Convention on the Rights of Persons with Disabilities: the difficult road from guardianship to supported decisionmaking", Hum. Rts. Brief, 2011, 19 (8); Barranco, María del Carmen; Cuenca, Patricia, Ramiro, Miguel A., "Capacidad jurídica y discapacidad: el artículo 12 de la Convención de derechos de las personas con discapacidad", Anuario Facultad de Derecho Universidad de Alcalá, 2012, Vol. V, pp. 53-80; BenAvides, Álvaro, "Modelos de capacidad jurídica: una reflexión necesaria a la luz del artículo 12 de la Convención Internacional sobre los Derechos de las Personas con Discapacidad", Tesis Doctoral, Universidad Carlos III, Madrid, 2013.

${ }^{69}$ Por ejemplo, CaIvano, Nicholas, "Conceptualizing Capacity: Interpreting Canada's Qualified Ratification of Article 12 of the UN Disability Rights Convention", WJ Legal Studies, 2014, vol. 4, No. 1; BACH, cit. (n. 35); BACH y Kerzner, cit. (n. 2).

${ }^{70}$ Por ejemplo, StaRvet, Jill, "The exercise of legal capacity, supported decision-making and Scotland's mental health and incapacity legislation: working with CRPD challenges", Laws, 2015, 4 (2); QuINN, cit. (n. 29); Pearl, Alex, "Article 12 of the United Nations Convention on the Rights of Persons with Disabilities and the Legal Capacity of Disabled People: The Way Forward", Leeds Journal of Law and Criminology, 2013, 1 (1); Werner, Shirli "Individuals with intellectual disabilities: a review of the literature on decision-making since the Convention on the Rights of People with Disabilities (CRPD)", Public Health Reviews, 2012, 34 (2).

${ }^{71}$ Por ejemplo, SÁnchez Gaitán, Sergio Camilo, "El artículo 12 de la Convención de los Derechos de las Personas con Discapacidad y su influencia en la jurisprudencia proferida en el marco de los sistemas regionales europeo e interamericano de protección de los derechos humanos", Revista Latinoamericana en Discapacidad, Sociedad y Derechos Humanos, 2017, 1 (1); BARTLETt, Peter; LewIs, Oliver; Thorold, Oliver, Mental disability and the European convention on human rights, Martinus Nijhoff Publishers, Leiden, 2007.

${ }^{72}$ Convención Interamericana para la Eliminación de todas las formas de Discriminación contra las Personas con Discapacidad, 1999, Promulgada en el Decreto N 99, 2002.
} 
países de Latinoamérica como Argentina, ${ }^{73}$ Perú, ${ }^{74}$ Costa Rica $^{75}$ y Colombia ${ }^{76}$ han legislado sobre la materia y están también en el proceso de replantearse el tratamiento de la capacidad jurídica de las PDM, de modo de ajustar sus legislaciones internas a los estándares fijados por la CDPD. Es necesario mirar su experiencia en la medida que sus realidades sociales y jurídicas se acercan más a las circunstancias de nuestro país.

\section{CASOS DE ESTUDIO DE EJERCICIO DE DERECHOS FUNDAMEN- TALES}

El estudio de casos paradigmáticos en que la capacidad para tomar decisiones involucre una necesidad de acomodar el ejercicio de autonomía y la necesidad de apoyos y cuidados se considera una etapa relevante para determinar si un determinado régimen general es adecuado. En este sentido, es necesario explorar si diferentes esferas de la vida jurídica y el ejercicio de diferentes derechos podrían requerir un tratamiento diferenciado, ${ }^{77} \mathrm{y}$ si la adopción de una reforma de un régimen general, que aborda la cuestión de la capacidad jurídica en términos binarios, podría repercutir negativamente en ciertos casos especiales.

La esfera del derecho privado y el ejercicio de derechos patrimoniales, por un lado, y la esfera del derecho penal e infraccional y el ejercicio de derechos procesales y sustantivos de defensa frente al poder (punitivo) estatal, por otro, son ambos paradigmáticos de abordaje de la capacidad jurídica. Mientras el régimen chileno de capacidad jurídica está establecido en el Código Civil y parece tener un afán de regular el tipo de actos jurídicos

\footnotetext{
${ }^{73}$ Código Civil y Comercial de la Nación, 2014 (Argentina). LAFFerRIERE, Jorge Nicolás; MuÑIz, Carlos, "Los procesos civiles relativos a la capacidad: de la Ley de Salud Mental al nuevo Código Civil y Comercial”, Pensar En Derecho, 2016, Nº9, pp. 141-196.

${ }^{74}$ Ley N² 29.973, 2012 (Perú); Decreto Legislativo N N 1417, 2018 (Perú). Véase, por ejemplo, Villarreal, Carla, "El reconocimiento de la capacidad jurídica de las personas con discapacidad mental e intelectual y su incompatibilidad con los efectos jurídicos de la interdicción y la curatela", Tesis de Magister, P. Universidad Católica del Perú, Lima, 2014.

${ }^{75}$ Ley N ${ }^{\circ}$ 9379, 2016 (Costa Rica).

${ }^{76}$ Ley N ${ }^{\circ}$ 1996, 2019 (Colombia).

${ }^{77}$ Esta perspectiva es adoptada, por ejemplo, por Flynn, Elionóir; ArsteIn-KersLAKE, Anna; DE Bhailís, Clíona; Serra, María L., Global Perspectives on Legal Capacity Reform: Our Voices, Our Stories, Routledge, London, 2018, donde se aborda diferenciadamente la esfera penal, contractual, amorosa, sexuales y médica.
} 
que son usuales en el tráfico privado, ${ }^{78}$ las reglas de inimputabilidad penal constituyen lo que parece ser la regulación general de la responsabilidad penal de las PDM. ${ }^{79}$ La regulación del ejercicio de derechos en el ámbito de la salud ha tenido asimismo un tratamiento importante por la doctrina. ${ }^{80}$ De los ámbitos recién señalados, la moción mencionada en la introducción de este trabajo se aproxima a la cuestión de la capacidad jurídica desde una perspectiva especialmente privatista, lo que no obsta a que, en la medida que es el Código Civil el que parece consagrar el régimen general de capacidad, ella tenga efectos expansivos en otras áreas del derecho.

En esta sección del trabajo se presentan tres ejemplos de derechos fundamentales que, si bien podrían ser afectados positivamente por una reforma a las reglas generales del Código Civil, constituyen buenas ilustraciones de las bondades de abordar la modificación del régimen de capacidad para el ejercicio de derechos de una manera que dé cuenta de la tremenda complejidad que existe en los diferentes derechos que son relevantes para las PDM y que en la actualidad se encuentran muchas veces fuera de su control. Esto puede contribuir a poner de relieve las ventajas de la práctica de tratar la capacidad jurídica mediante la adopción de reglas diferenciadas para situaciones específicas, no solo respecto de los sujetos involucrados, sino también respecto a los derechos o intereses implicados en la adopción de decisiones por parte de tales sujetos. Esta técnica pone de relieve, la complejidad de la regulación de la capacidad jurídica.

\section{Derechos politicos}

Un primer caso de estudio podría explorar los derechos políticos de las PDM. En esta línea, el art. 29 de la CDPD establece que los "Estados Partes garantizarán a las personas con discapacidad los derechos políticos y la

\footnotetext{
${ }^{78}$ Véase, por ejemplo, Barcia LeHmann, Rodrigo, "Algunas críticas al Derecho Común y especialmente a la regulación de las incapacidades respecto del adulto mayor en el ordenamiento jurídico chileno", Revista chilena de derecho privado, 2014, n² 23; Corral, Hernán, "Interdicción de personas que sufren trastorno de dependencia a la cocaína", Revista de derecho (Valdivia), 2011, 24 (2), pp. 31-64; Frigerio, César; Letelier, Cristián, "Sobre la Capacidad de los Dementes y Sordomudos", Revista Chilena de Derecho, 1992, 19 (1).

${ }^{79}$ Véase, por ejemplo, Garrido, Mario, Derecho Penal. Parte general, vol. 1, Editorial Jurídica de Chile, Santiago, 2001; Cury, Enrique, Derecho Penal. Parte general, vol. 1, Editorial Jurídica de Chile, Santiago, 2005.

${ }^{80}$ MuÑoz, María Teresa; Lucero, Boris Andrés, "Aspectos legales y bioéticos de intervenciones e investigaciones en personas con discapacidad intelectual en Chile", Acta bioethica, 2014, 20 (1).
} 
posibilidad de gozar de ellos en igualdad de condiciones". Además señala que se comprometerán a que las PDM "puedan participar plena y efectivamente en la vida política y pública en igualdad de condiciones con las demás (...) incluidos el derecho y la posibilidad de las personas con discapacidad a votar y ser elegidas". Frente a las obligaciones establecidas por la CDPD, la Ley 20.183 modificó la modalidad tradicional de votación presencial para incorporar en nuestro sistema jurídico el voto asistido para las PD. Sin embargo, frente a ello, el art. 16 de la Constitución sigue estableciendo que el derecho a sufragio se suspende por interdicción por causa de demencia. La exclusión electoral de PDM se ha justificado tradicionalmente como una forma de garantizar la integridad de la elección, argumentando que las PDM no son suficientemente autónomas e independientes para sufragar ${ }^{81} \mathrm{O}$ que carecen de las habilidades cognitivas, la virtud cívica o la conciencia moral necesaria para sufragar debidamente. ${ }^{82}$ Sin embargo, la literatura especializada ha cuestionado que estos argumentos tradicionales tengan asidero. ${ }^{83}$

La moción comentada al comienzo de este artículo plantea la eliminación del numeral respectivo del art. 16. Sin embargo, tal reforma no se hace cargo de una serie de barreras informales que afectan a las PDM en su acceso efectivo al sufragio ${ }^{84} \mathrm{y}$ que deberían ser abordadas de una manera sistemática, creando medidas de accesibilidad adecuadas. Ello implica, sólo para presentar un ejemplo, pensar, más allá de lo ya resuelto por el Tribunal Constitucional, cuál es el rol y la forma que deben adoptar los apoyos y salvaguardas en el contexto de una elección que está gobernada por el principio del sufragio secreto. ${ }^{85}$

\footnotetext{
${ }^{81}$ GÁlvez MuÑoz, Luis, El derecho a voto de los discapacitados y otras personas vulnerables, Tirant lo Blanch, Murcia, 2009, pp. 82 y ss.

82 Comité de las Naciones Unidas sobre los Derechos de las Personas con Discapacidad, cit. (n. 3), p. 48.

${ }^{83}$ RaAd, Raymond; Karlawish, Jason; Appelbaum, Paul, "The capacity to vote of persons with serious mental illness", Psychiatric Services, 2009, 60 (5), pp. 624-628; Corrigan, Patrick; Markowitz, Fred; Watson, Amy, "Structural levels of mental illness stigma and discrimination", Schizophrenia bulletin, 2004, 30 (3), pp. 481-491; Agran, Martin; McLean, William; Kitchen A, Katherine, “"My Voice Counts, Too": Voting Participation among Individuals with Intellectual Disability", Intellectual and Developmental Disabilities, 2016, 54 (4).
}

${ }^{84}$ Véase Marshall, Pablo; Abollado, Patricia, "El sufragio de las personas con discapacidad intelectual en Chile", en: Espejo, N.; Lathrop, F. (eds.), Derecho y Discapacidad Intelectual, Thomson Reuters, Santiago, 2019.

${ }^{85}$ En su Sentencia Rol 745-07, el Tribunal Constitucional chileno consideró que el sufragio asistido era constitucional. Se considera que, por un lado, quedan toda otra serie de hipótesis de apoyo por explorar, 


\section{Derechos sexuales y reproductivos}

Un segundo ejemplo es uno de los derechos que las PDM ven rutinariamente afectados: sus derechos sexuales y reproductivos. La CDPD señala que las PD deben tener acceso a programas de salud en el ámbito de la salud sexual y reproductiva (art. 25), que no deben ser discriminadas en cuestiones relacionadas con el matrimonio, la familia, la paternidad y las relaciones personales (art. 23.1) y que tienen derecho a decidir libremente y de manera responsable el número de hijos que quieren tener, y a mantener su fertilidad, en igualdad de condiciones respecto de las demás personas (art. 23.2).

El Comité, por su parte, ha señalado que los regímenes de sustitución de capacidad influyen de manera importante en que "las mujeres con discapacidad presenten elevadas tasas de esterilización forzada, y con frecuencia se vean privadas del control de su salud reproductiva y de la adopción de decisiones al respecto, al darse por sentado que no son capaces de otorgar su consentimiento para las relaciones sexuales". ${ }^{86}$ No obstante este diagnóstico crítico, algunas de las razones que se ofrecen para limitar o regular el derecho a la autonomía sexual y reproductiva de las PDM son atendibles. Reciente literatura ha abordado la prevención del embarazo no deseado, el derecho a decidir practicarse un aborto, el acceso a clínicas de fertilidad, la situación de las PDM como padres y las formas de proteger a las PDM frente a abusos sexuales por parte de terceros (muchas veces con embarazos resultantes), desde una perspectiva respetuosa de su autonomía. ${ }^{87}$ Todas estas son cuestiones delicadas y sumamente complejas. Muchas veces involucran intereses y derechos de terceras personas, especialmente aquellos que ejercen labores de cuidado, lo que hace desaconsejable un

\footnotetext{
y que, por otro lado, hace falta justificar de una manera más contundente, especialmente de cara a la importancia que tiene el secreto en el derecho constitucional (y en la propia CDPD) el levantamiento de secreto que implica el voto asistido.

${ }^{86}$ Comité de las Naciones Unidas sobre los Derechos de las Personas con Discapacidad, cit. (n. 3), p. 35; véase, para el caso chileno, Casas, Lidia; Salas, Sofía; Álvarez, Juan José, "La práctica de la esterilización en niñas y mujeres competentes y con discapacidad psíquica o intelectual en Chile", en: Vial, Tomás (ed.), Informe Anual sobre Derechos Humanos en Chile, Eds. Universidad Diego Portales, Santiago, 2016, pp. 173-216.

${ }^{87}$ Por ejemplo, Perlin, Michael; Lynch, Alison, Sexuality, Disability, and the Law: Beyond the Last Frontier?, Springer, Basingstoke, 2016; BonI-SAEnz, Alexander, "Sexuality and Incapacity", Ohio State Law Journal, 2015, 76 (6); SERIES, Lucy, "Mental capacity and the control of sexuality of people with intellectual disabilities in England and Wales", en: Shakespeare, Tom (ed.), Disability research today: International perspectives, Routledge, London, 2015.
} 
enfoque simplista que, ya exacerbe el ejercicio de la autonomía de las PDM desatendiendo otros elementos, ya prive a estas personas de todo espacio para el ejercicio de sus derechos sexuales y reproductivos. Por otro lado, estamos acostumbrados a pensar en la vida sexual y afectiva como una cuestión que no puede estar mediada por terceras personas o en que nuestra participación en ella normalmente exige la exclusión de terceras personas que no sean las directamente involucradas. Ello supone la necesidad de pensar con detenimiento cuál podría ser el rol que los apoyos y salvaguardas en esta área de la vida - especialmente para apoyar la construcción de relaciones íntimas por parte de personas que tienen pocos o nulos recursos para comunicarse - y cómo estos apoyos deben configurarse de manera que no desvirtúen las aspiraciones de los involucrados. Todas estas situaciones desafían nuestra comprensión habitual de los derechos sexuales y reproductivos como un espacio de autonomía individual inviolable.

\section{Libertad personal}

Finalmente, el tercer ejemplo es la afectación de la libertad personal, especialmente en los casos en que las PDM son sujetas a internación en un recinto de salud mental sin su consentimiento o con el consentimiento de aquel que lo sustituye en la adopción de las decisiones. Si bien este ejemplo es un caso específico de una cuestión que ha recibido mucho más tratamiento en nuestro país, a propósito de la dictación de la Ley 20.584, que regula el consentimiento a someterse a tratamientos de salud, las internaciones no voluntarias en recintos de salud mental siguen siendo un caso de afectación de derechos alejado del interés público. El Comité ha sostenido que estas prácticas son atentatorias contra el art. 12 y el art. 14 de la CDPD y que deben eliminarse, además de establecer mecanismos para examinar situaciones en que personas son internadas sin su consentimiento expreso. ${ }^{88}$ Una cuestión especialmente relevante en relación con este caso es que el análisis del ejercicio de la libertad personal pasa por considerar cuáles son los efectos de un régimen de apoyo a la toma de decisiones que garantice la autonomía de las PDM en áreas específicas del sistema jurídico como es el área de la regulación de la salud mental, en que el conflicto entre las premisas del modelo social y del modelo médico de discapacidad

${ }^{88}$ Comité de las Naciones Unidas sobre los Derechos de las Personas con Discapacidad, cit. (n. 3), p. 40. 
están destinados a colisionar. ${ }^{89}$ En Chile, como se ha mencionado, subsisten instancias de internación forzosa en recintos médicos, reguladas por la Ley 20.584 y el Código Sanitario. No obstante el gran debate subsistente, la jurisprudencia internacional y la literatura han avanzado hacia un consenso acerca de que el consentimiento libre e informado (con estándares de debido proceso: audiencia judicial, asistencia jurídica, posibilidad de apelar) es necesario para el internamiento de las PDM. Sin embargo, incluso en sus más radicales formulaciones, se admite la necesidad del internamiento involuntario, como medida excepcional y de ultima ratio, sólo cuando exista un riesgo inmediato para la PDM o para terceros..$^{90}$ Determinar claramente dichos casos, asignar roles institucionales a los distintos actores involucrados y producir un cambio radical en la comprensión paternalista de la intervención médica, supone la necesidad de un cuidadoso esfuerzo analítico y de diálogo interdisciplinar.

Como puede observarse, esta selección de derechos de diversa naturaleza supone una diversidad de áreas en las que las PDM son excluidas del disfrute de sus derechos. Ellos son, asimismo, derechos que reciben una consagración expresa en la CDPD y han sido identificados como áreas prioritarias para la inclusión social de las PDM. Lo más importante de destacar es que el ejercicio de autonomía que estos derechos involucrarían se enfrenta con razones de diferente entidad que hablan en favor de una restricción de dicha autonomía. Mientras las razones para la limitación de los derechos políticos son más débiles, y en ese caso los principales problemas son de accesibilidad, la limitación de la autonomía sexual y reproductiva puede ser defendida por argumentos más contundentes que obedezcan a intereses a largo plazo de terceras personas. Finalmente, la limitación de la libertad personal podría depender de razones urgentes como la puesta en peligro de la vida de la misma PDM.

\footnotetext{
${ }^{89}$ Gooding, cit. (n. 67).

${ }^{90}$ Por ejemplo, Quinn, Gerard; Degener, Theresia (Coords.), Derechos humanos y discapacidad: Uso actual y posibilidades futuras de los instrumentos de derechos humanos de las Naciones Unidas en el contexto de la discapacidad, Naciones Unidas, Nueva York - Ginebra, 2002; Ferreirós Marcos, Carlos, Salud mental y derechos humanos, CERMI, Madrid, 2014.
} 


\section{CONCLUSIONES}

La legislación doméstica general sobre capacidad jurídica y ejercicio de derechos de las personas con discapacidad mental todavía no ha adecuado su régimen de capacidad a los estándares internacionales de protección de los derechos de las personas con discapacidad. En otras palabras, el derecho interno sobre la materia, caracterizado por la presencia del régimen de incapacidad absoluta en el Código Civil, no está adecuado a los estándares fijados por la CDPD, que se expresan de forma general pero incompleta en la Ley 20.422.

El resultado esperado de una investigación pormenorizada de los elementos aquí identificados debería llevar a una propuesta acerca de un régimen de capacidad jurídica para las PDM que sean compatibles con las obligaciones internacionales del Estado de Chile y que sirva para orientar una reforma legislativa en la materia. Ello pasa, necesariamente, por elaborar una serie de elementos. En primer lugar, por identificar un marco conceptual y teórico apto para resolver problemas de ejercicio de derechos de las PDM. En segundo lugar, prestar atención a los desarrollos en el derecho comparado que han implementado o intentado implementar las obligaciones fijadas por la CDPD en relación a los regímenes de capacidad jurídica para dichas personas. Ello permitirá la determinación precisa de las obligaciones que se siguen de la subscripción del CDPD para nuestro país y la determinación de las opciones que el Estado de Chile tiene para su cumplimiento. En tercer lugar, por proponer estándares y determinar el régimen jurídico adecuado para el ejercicio de derechos en distintas áreas de la vida. Como se diera cuenta, ello no sólo involucra la propuesta de una regulación general civil o penal sino un análisis de áreas como la autonomía sexual y reproductiva, el ejercicio de los derechos de participación política y el ejercicio del derecho a la libertad personal frente intervenciones no voluntarias.

La debida consideración de estos elementos permitirá formular las bases de un régimen que equilibre adecuadamente el ejercicio de la autonomía que las PDM son capaces de alcanzar y las necesidades de apoyo y cuidado que como sujetos en situación de vulnerabilidad requieren para esa finalidad. Admitiendo la vulnerabilidad de las PDM, un adecuado régimen de cuidado podría, tanto contribuir al ejercicio de su autonomía (como es el caso de las medidas de apoyo a la toma de decisiones), como justificar, en ciertas circunstancias, restricciones a la misma (como podría ser el caso de medidas en contra de acciones que inflijan daño a sí mismos o a terceros, o que sean constitutivas de delito). 


\section{BIBLIOGRAFÍA CITADA}

a) Doctrina y documentos citados

Agran, Martin; McLean, William; Kitchen A, Katherine, "My Voice Counts, Too: Voting Participation Among Individuals with Intellectual Disability", Intellectual and Developmental Disabilities, 2016, 54 (4), pp. 285-294.

$\mathrm{BACH}$, Michael, "El derecho a la capacidad jurídica en la Convención de la ONU sobre los derechos de las personas con discapacidad", en Bariffi, F., Palacios, A. (Coords.), Capacidad jurídica, discapacidad y derechos humanos, Editorial EDIAR, Buenos Aires, 2011.

BACH, Michael; Kerzner, Lana, "A new paradigm for protecting autonomy and the right to legal capacity", Law Commission of Ontario, Ontario, 2014, 196 p., en línea: https://www.lco-cdo.org/wp-content/uploads/2010/11/disabilitiescommissioned-paper-bach-kerzner.pdf .

Barcia LeHmann, Rodrigo, "Algunas críticas al Derecho Común y especialmente a la regulación de las incapacidades respecto del adulto mayor en el ordenamiento jurídico chileno", Revista chilena de derecho privado, 2014, $\mathrm{n}^{\circ} 23$, pp. 57-86.

BARIFFI, Francisco, El régimen jurídico internacional de la capacidad jurídica de las personas con discapacidad, CERMI, España, 2016

BARIFF, Francisco; Palacios, Agustina, Capacidad Jurídica y Discapacidad: México. Cuaderno de Trabajo $\mathrm{n}^{\circ}$ 12, Eds. FUTUEX (Fundación Tutelar de Extremadura), Bajadoz, 2009.

Barnes, Colin; Mercer, Geof, Exploring Disability, Polity Press, Cambridge, 2010.

Barranco, María del Carmen; Cuenca, Patricia, Ramiro, Miguel A., "Capacidad jurídica y discapacidad: el artículo 12 de la Convención de derechos de las personas con discapacidad", Anuario Facultad de Derecho Universidad de Alcalá, 2012, Vol. V, pp. 53-80.

Bartlett, Peter; Lewis, Oliver; Thorold, Oliver, Mental disability and the European convention on human rights, Martinus Nijhoff Publishers, Leiden, 2007.

Beckett, Angharad, Citizenship and vulnerability: Disability and issues of social and political engagement, Palgrave Macmillan, Londres, 2006.

BenAvides, Álvaro, "Modelos de capacidad jurídica: una reflexión necesaria a la luz del artículo 12 de la Convención Internacional sobre los Derechos de las Personas con Discapacidad”, Tesis Doctoral, Universidad Carlos III, Madrid, 2013.

Benavides, Álvaro, "Capacidad jurídica: una reflexión necesaria a la luz de la Convención sobre los Derechos de las Personas con Discapacidad”, Anuario de Derechos Humanos UDP, 2015, N¹1, pp. 39-56.

Boni-SAEnz, Alexander, "Sexuality and Incapacity", Ohio State Law Journal, 
2015, 76 (6), pp. 1201-1253.

Browning, Michelle; Bigby, Christine; Douglas, Jacinta, "Supported decision making: Understanding how its conceptual link to legal capacity is influencing the development of practice", Research and Practice in Intellectual and Developmental Disabilities, 2014, 1 (1), pp. 34-45.

CaIvano, Nicholas, "Conceptualizing Capacity: Interpreting Canada's Qualified Ratification of Article 12 of the UN Disability Rights Convention", WJ Legal Studies, 2014, vol. 4, No. 1.

Cámara de Diputados (Eds.), Evaluación de la Ley 18.600. Establece normas sobre discapacitados mentales, Departamento de Evaluación de la ley, Cámara de Diputados, Valparaíso, 2013, 75 pp., en línea: https://obtienearchivo.bcn.cl/ obtienearchivo?id=documentos/10221.1/44459/1/informe_final_ley_18600.pdf.

CAREY, Allison, On the margins of citizenship, Temple University Press, Philadelphia, 2009.

CAREY, Allison, "The Capacity Contract: Intellectual Disability and the Question of Citizenship", Disability Studies Quarterly, 2015, 35 (4).

Casas, Lidia; Salas, Sofía; Álvarez, Juan José, "La práctica de la esterilización en niñas y mujeres competentes y con discapacidad psíquica o intelectual en Chile", en: Vial, Tomás (ed.), Informe Anual sobre Derechos Humanos en Chile, Eds. Universidad Diego Portales, 2016, pp. 173-216.

Comité de las Naciones Unidas sobre los Derechos de las Personas con Discapacidad (Eds.), Observación General $N^{o} 1$ de 2014 del Comité sobre los Derechos de las Personas con Discapacidad de la Organización de Naciones Unidas, Naciones Unidas, s/l., 2014.

Comité de las Naciones Unidas sobre los Derechos de las Personas con DisCAPACIDAD (Eds.), Observaciones finales sobre el informe inicial de Chile (CRPD/C/CHL/CO/1), Naciones Unidas, Nueva York, 2016, 10 pp, disponible en línea: https://acnudh.org/comite-sobre-los-derechos-de-las-personas-condiscapacidad-cre/.

Congreso Nacional, "Proyecto de Ley: Modifica diversos textos legales con el objeto de eliminar la discriminación en contra de personas con discapacidad intelectual, cognitiva y psicosocial, y consagrar su derecho a la autonomía", Boletín $\mathrm{N}^{\circ} 12441-17,2019$, proyecto y estado de tramitación disponibles en línea: https:// www.camara.cl/legislacion/ProyectosDeLey/tramitacion.aspx?prmID=12972.

CORRAL, Hernán, "Interdicción de personas que sufren trastorno de dependencia a la cocaína", Revista de derecho (Valdivia), 2011, 24 (2), pp. 31-64.

Corrigan, Patrick; Markowitz, Fred; Watson, Amy, "Structural levels of mental illness stigma and discrimination", Schizophrenia bulletin, 2004, 30 (3), pp. 481-491.

Cury, Enrique, Derecho Penal. Parte general, vol. 1, Editorial Jurídica de Chile, Santiago, 2005. 
DAvis, Lennard (ed.), The disability studies reader, Taylor \& Francis, Abingdon, 2006.

DHANDA, Amita, "Legal capacity in the disability rights convention: stranglehold of the past or lodestar for the future", Syracuse J. Int'l L. \& Com., 2007, vol. 34.

Dinerstein, Robert, "Implementing legal capacity under Article 12 of the UN Convention on the Rights of Persons with Disabilities: the difficult road from guardianship to supported decision-making", Hum. Rts. Brief, 2011, 19 (8).

Fallon-Kund, Marie; BickenbachB, Jerome, "New Legal Capacity Laws and the United Nations Convention on the Rights of Persons with Disabilities: An Overview of Five Countries in Europe", European Journal of Health Law, 2017, 24 (3), pp. 285-310.

Ferreirós Marcos, Carlos, Salud mental y derechos humanos, CERMI, Madrid, 2014.

FigueroA, Miguel Ángel; InostrozA, Hernán, Discapacidad y Salud Mental: una visión desde el SENADIS, Alvimpress, Santiago, 2016.

Fineman, Martha, The Autonomy Myth. A Theory of Dependency, The New Press, New York, 2004.

Flynn, Elionóir; Arstein-Kerslake, Anna; de Bhailís, Clíona; Serra, María L., Global Perspectives on Legal Capacity Reform: Our Voices, Our Stories. Routledge, London, 2018.

Fraser, Nancy; Honneth, Axel, Redistribution or recognition? A politicalphilosophical exchange, Verso, New York, 2003.

Frigerio, César; Letelier, Cristián, "Sobre la Capacidad de los Dementes y Sordomudos", Revista Chilena de Derecho, 1992, 19 (1).

GÁlvez Muñoz, Luis, El derecho a voto de los discapacitados y otras personas vulnerables, Tirant lo Blanch, Murcia, 2009.

Garrido, Mario, Derecho penal. Parte general, Editorial Jurídica, Santiago, vol. 1, 2001. 1982.

GiLligan, Carol, In a different voice, Harvard University Press, Massachusetts,

Gooding, Piers, "Supported decision-making: a rights-based disability concept and its implications for mental health law", Psychiatry, Psychology and Law, 2013, 20 (3), pp. 431-451.

Held, Virginia, The Ethics of Care: Personal, Political, and Global, Oxford University Press, Oxford, 2006.

Honneth, Axel, The struggle for recognition: The moral grammar of social conflicts, The MIT Press, Massachusetts, 1995.

INHAHEIMO, Heikki, "Personhood and the social inclusion of people with disabilities: a recognition-theoretical approach", en KRISTIANSEN, Kristjana; Vehmas, Simo; Shakespeare, Tom (Eds.), Arguing about disability: Philosophical 
perspectives, Routledge, London, 2008.

Instituto Nacional de Derechos Humanos, Situación de los Derechos humanos en Chile, Informe Anual, INDH, Santiago, 2014, 334 pp., en línea: https:// bibliotecadigital.indh.cl/handle/123456789/740.

Kittay, Eva, Love's Labor: Essays on Women, Equality, and Dependency, Routledge, London, 1999.

Kittay, Eva; Feder, Ellen, The Subject of Care: Feminist Perspectives on Dependency, Rowman \& Littlefield, Maryland, 2003.

Kittay, Eva; Carlson, Licia, Cognitive disability and its challenge to moral philosophy, John Wiley \& Sons, New Jersey, 2010.

Kristiansen, Kristjana; Vehmas, Simo; Shakespeare, Tom (Eds.), Arguing about disability: Philosophical perspectives, Routledge, London, 2008.

LAFFERriere, Jorge Nicolás; MuÑIz, Carlos, "Los procesos civiles relativos a la capacidad: de la Ley de Salud Mental al nuevo Código Civil y Comercial", Pensar En Derecho, 2016, No 9, pp. 141-196.

Lyon, Alberto, Personas Naturales, Ediciones Universidad Católica de Chile, Santiago, 2007.

Marshall, Pablo; Abollado, Patricia, "El sufragio de las personas con discapacidad intelectual en Chile", en: Espejo, N.; Lathrop, F. (eds.), Derecho y Discapacidad Intelectual, Thomson Reuters, Santiago, 2019.

Ministerio de Desarrollo Social, Informe de Desarrollo Social 2016, Gobierno de Chile, Santiago, 2016.

Minow, Martha, Making All the Difference. Inclusion, exclusion and American law, Cornell University Press, New York, 1990.

MuÑoz, María Teresa; LuCERo, Boris Andrés, "Aspectos legales y bioéticos de intervenciones e investigaciones en personas con discapacidad intelectual en Chile", Acta bioethica, 2014, 20 (1), pp. 61-70.

Nussbaum, Martha, Las fronteras de la justicia: consideraciones sobre la exclusión, Paidós, Barcelona, 2006.

Nussbaum, Martha, Creating capabilities, Harvard University Press, Massachusetts, 2011.

Nussbaum, Martha, Las mujeres y el desarrollo humano, Herder Editorial, Barcelona, 2012.

Oliver, Michael; Bochel, Hugh, "The politics of disablement”, International Journal of Rehabilitation Research, 1991, 14 (2).

Palacios, Agustina, El modelo social de discapacidad: origenes, caracterización y plasmación en la Convención Internacional de los Derechos de las Personas con Discapacidad, CINCA, Madrid, 2008.

Pearl, Alex, "Article 12 of the United Nations Convention on the Rights of Persons with Disabilities and the Legal Capacity of Disabled People: The Way Forward", Leeds Journal of Law and Criminology, 2013, 1 (1). 
PERLIN, Michael, "A Change is Gonna Come: The Implications of the CRPD for the Domestic Practice of Constitutional Mental Disability Law", Northern Illinois University Law Review, 2008, 29 (3), pp. 483-498.

Perlin, Michael; Lynch, Alison, Sexuality, Disability, and the Law: Beyond the Last Frontier?, Springer, Basingstoke, 2016.

Pothier, Dianne; Devlin, Richard, Critical disability theory: Essays in philosophy, politics, policy, and law, UBC press, Vancouver, 2006.

QuinN, Gerard, "Personhood and Legal Capacity Perspectives on the Paradigm Shift of Article 12 CRPD", Conferencia, Harvard Law School, Boston, 20.02.2010.

QuinN, Gerard; Degener, Theresia (Coords.), Derechos humanos y discapacidad: Uso actual y posibilidades futuras de los instrumentos de derechos humanos de las Naciones Unidas en el contexto de la discapacidad, Naciones Unidas, Nueva York - Ginebra, 2002.

Quinn, Gerard; ArsteIn-Lerslake, Anna, "Restoring the Human in Human Rights-Personhood and Doctrinal Innovation in the UN Disability Convention", in Douzinas, C., Gearty, C. (eds.), The Cambridge companion to human rights law, Cambridge University Press, Cambridge, 2012, 36-55.

RaAD, Raymond; Karlawish, Jason; Appelbaum, Paul, "The capacity to vote of persons with serious mental illness", Psychiatric Services, 2009, 60 (5), pp. 624-628.

Rawls, John, Una teoría de la justicia, Fondo de cultura económica, Santiago, 2012.

Rogers, Chrissie, Intellectual Disability and Being Human: A Care Ethics Model, Routledge, London, 2016.

SÁnchez Gaitán, Sergio Camilo, "El artículo 12 de la Convención de los Derechos de las Personas con Discapacidad y su influencia en la jurisprudencia proferida en el marco de los sistemas regionales europeo e interamericano de protección de los derechos humanos", Revista Latinoamericana en Discapacidad, Sociedad y Derechos Humanos, 2017, 1 (1).

SEN, Amartya, "The place of capability in a theory of justice", en: BRIGHOUSE, H.; Robeyns, I. (Eds.), Measuring justice: primary goods and capabilities, Cambridge University Press, Cambridge, 2010, pp. 239-253.

SERIES, Lucy, "Mental capacity and the control of sexuality of people with intellectual disabilities in England and Wales", en: Tom Shakespeare (ed.), Disability research today: International perspectives, Routledge, London, 2015, pp. 149-165.

Servicio Nacional de la Discapacidad, Cuestionario a los Estados Partes de la Relatora Especial sobre los Derechos de las Personas con Discapacidad, SENADIS, Santiago, 2014.

Sevenhuijsen, Selma, Citizenship and the ethics of care, Psychology Press, New York, 1998. 
ShaKesPeAre, Tom, "The social model of disability", en: Davis, Lennard, The disability studies reader, Taylor \& Francis, Abingdon, 2006.

Silva, Paula, La capacidad jurídica de las personas con discapacidad intelectual, Thomson Reuters, Santiago, 2017.

STARVET, Jill, "The exercise of legal capacity, supported decision-making and Scotland's mental health and incapacity legislation: working with CRPD challenges", Laws, 2015, 4 (2), pp. 296-313.

Tremain, Shelley, Foucault and the Government of Disability, University of Michigan Press, Ann Arbor, 2015.

Villarreal, Carla, "El reconocimiento de la capacidad jurídica de las personas con discapacidad mental e intelectual y su incompatibilidad con los efectos jurídicos de la interdicción y la curatela", Tesis de Magister, P. Universidad Católica del Perú, Lima, 2014.

WARrEN, Kacey Brooke, Recognizing justice for citizens with cognitive disabilities, Lexington Books, Maryland, 2015.

WERNER, Shirli "Individuals with intellectual disabilities: a review of the literature on decision-making since the Convention on the Rights of People with Disabilities (CRPD)", Public Health Reviews, 2012, 34 (2).

\section{b) Jurisprudencia}

Corte de Apelaciones de Santiago, 30 de mayo de 2016, Rol (civil) N 13042016.

Tribunal Constitucional, 29 de marzo de 2007, Rol N 745-07.

\section{c) Normativa}

Código Civil.

Código Civil y Comercial de la Nación, 2014 (Argentina).

Código de Procedimiento Civil.

Código Procesal Penal.

Código Sanitario.

Constitución Política de la República de Chile.

Convención sobre los Derechos de las Personas con Discapacidad, 2006.

Convención Interamericana para la Eliminación de todas las formas de Discriminación contra las Personas con Discapacidad, 1999.

Decreto Legislativo No 1417, 2018 (Perú).

Decreto N47/2013 del Ministerio de Salud.

Ley 18.600, Establece normas sobre deficientes mentales, 1987.

Ley 18.700, Ley orgánica constitucional sobre votaciones populares y escrutinios, 1988. 
Ley 19.620, Dicta normas sobre adopción de menores, 1999.

Ley 19.947, Establece nueva ley de matrimonio civil, 2004.

Ley 20.183, Modifica la ley 18.700, orgánica constitucional sobre votaciones populares y escrutinios, con el objeto de reconocer el derecho a la asistencia en el acto de votar para las personas con discapacidad, 2007.

Ley 20.422, Establece normas sobre igualdad de oportunidades e inclusión social de personas con discapacidad, 2010.

Ley 20.584, Regula los derechos y deberes que tienen las personas en relación con acciones vinculadas a su atención en salud, 2012.

Ley 20.609, Establece medidas contra la discriminación, 2012.

Ley 21.015, Incentiva la inclusión de personas con discapacidad al mundo laboral, 2017.

Ley 1996, Por medio de la cual se establece el régimen para el ejercicio de la capacidad legal de las personas con discapacidad mayores de edad, 2019 (Colombia).

Ley 29.973, Ley general de la persona con discapacidad, 2012 (Perú).

Ley 9.379, Ley para Promoción de la Autonomía Personal de las Personas con Discapacidad, 2016 (Costa Rica). 